\title{
INCOMPETENT CONGENITAL BICUSPID RIGHT ATRIO-VENTRICULAR VALVE
}

\author{
BY \\ N. COULSHED \\ From the Regional Cardiac Centre, Sefton General Hospital, Liverpool
}

Congenital right atrio-ventricular incompetence is uncommon, but when present usually shows characteristic physical signs. The case to be presented was regarded during the last year of his life as having Ebstein's anomaly, the correct diagnosis being established at necropsy.

\section{Case Report}

A man, aged 18, was first seen at the Cardiac Centre in 1954, when he was admitted because of fainting attacks during the previous three months. In 1948, when aged 12, his heart was found to be enlarged, but no ætiological diagnosis.was made, beyond the possibility of cardiac amyloidosis.

From 1948 until early 1954 his main complaints were of constant fatigue and slight dyspnœa on effort. The attacks of faintness were characterized by a very rapid heart action for a few seconds, followed by transient loss of consciousness, recovery occurring rapidly with no after-effects. Observed during one of these attacks, his pulse rate rose to over 150 , with an apparently regular rhythm but a very small pulse volume. The rate fell to 60 in a few seconds, and he recovered consciousness. Unfortunately, we were unable to obtain any electrocardiograms during these attacks.

On examination, the liver was just palpable and firm, but no other evidence of congestive cardiac failure was found, and he was not cyanosed, either at this stage or later. The heart rhythm was regular and 80 a minute. The brachial blood pressure was $110 / 90 \mathrm{~mm}$. The apex beat was just palpable in the midaxillary line, in the sixth interspace; no præcordial pulsation was seen or felt, and no thrills were palpated. The heart sounds were noted as being very quiet, no murmurs or added sounds were heard, and there were no abnormal signs in the lungs.

The electrocardiogram showed sinus rhythm with ventricular ectopic beats, evidence of right atrial hypertrophy, and a partial right bundle-branch block. Chest X-ray (Fig. 1) and radioscopy revealed an enormous heart, with a narrow vascular pedicle, a concavity in the region of the pulmonary conus, and what appeared to be enlargement of the right atrium, and both ventricles. Pulsation was present but much diminished along the whole contour, and the œesophagus was not displaced. The lungs were oligæmic.

A tentative diagnosis of constrictive pericarditis was made, although many anomalous features were present, and thoracotomy was undertaken in July, 1954 . On exposing the heart, a normal pericardium was found, but the right and left ventricles could not be identified, although the impression of the surgeon at the time was that the chamber he could palpate anteriorly was the right ventricle. Post-operative recovery was uneventful, but a year after operation the first signs of severe congestive cardiac failure appeared, and worsened until in May, 1956, he was readmitted with marked ascites and odema of his legs, back, and genitalia. The jugular veins were filled to a level $8 \mathrm{~cm}$. above the sternal angle, but no pulsation could be observed. The liver, palpated after the ascites had been drained, was firm, painless, and did not pulsate.

The pulse was of very poor volume, the rhythm completely irregular, and the systolic blood pressure was $110 \mathrm{~mm}$. Hg. The apex beat was just palpable, now in the posterior axillary line. The heart sounds were irregular but otherwise unchanged, and there was no evidence of pulmonary œdema. The radioscopic appearances were as before, but his electrocardiogram from this time onwards showed varying arrhythmias, with atrial flutter, atrial fibrillation, and ventricular ectopic beats.

Reappraisal of the diagnosis led us to believe that this man had an Ebstein's anomaly, the evidence in favour being the enlarged, quietly acting heart, the episodes of paroxysmal tachycardia, the electrocardiographic findings, and the oligæmic lung fields. Cardiac catheterization was, therefore, not performed.

A more prolonged attack of unconsciousness occurred on December 28, 1956, from which the patient did not recover. No medical attendance was forthcoming until after death, but presumably he had a more prolonged and fatal attack of tachycardia. 


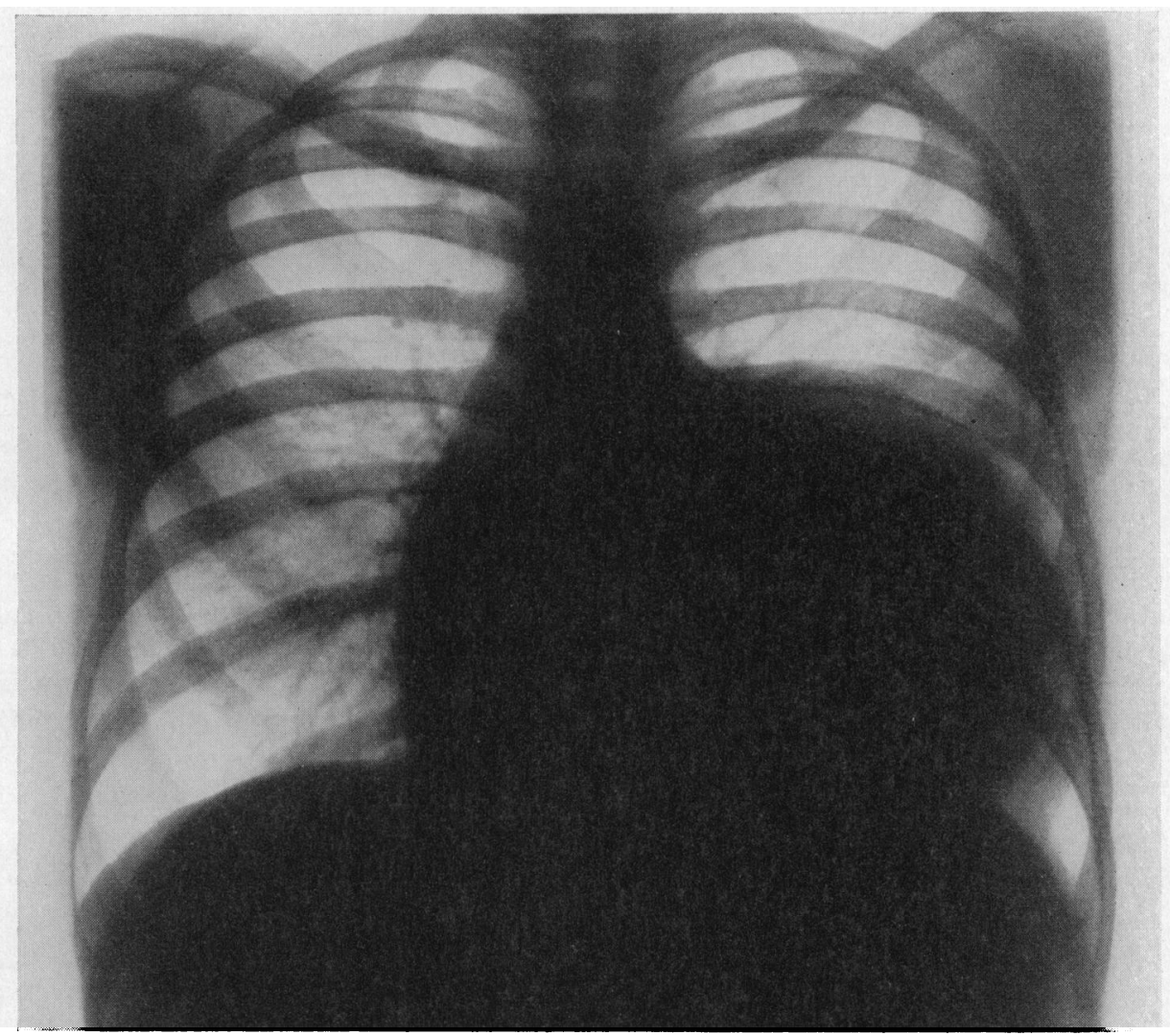

Fig. 1.-Postero-anterior radiograph, showing the enlarged heart, and oligæmic lung fields.

Necropsy was performed two days later. The liver showed severe cardiac cirrhosis, and gross ascites was present. Extensive dissection of both lungs showed no macroscopic abnormality, all the pulmonary vessels being normal. No fluid was present in the pleural cavities.

The heart (Fig. 2) weighed $580 \mathrm{~g}$. and occupied a large proportion of the left hemithorax. Inspected in situ, the left ventricle could not be identified, but after removal of the whole organ, the left atrium and ventricle were seen posteriorly. Both chambers were slightly dilated, and the wall of the left ventricle was $12 \mathrm{~mm}$. thick. Over the apex and adjoining septum of the left ventricle, the endocardium was opaque, white and thickened, sections of this area showing definite subendocardial fibrosis. The same appearances were present in the left atrium. The mitral and aortic valves were normal, the foramen ovale was sealed, and the septa were intact. The coronary arteries were normal in every respect.

The right atrium was dilated, with an approximate capacity of $350 \mathrm{ml}$. The wall was hypertrophied and much mural thrombus was present in the atrium itself and its appendage. Both venæ cavæ were normal, as was the coronary sinus. The tricuspid valve ring was normally situated, but was dilated to $19 \cdot 5 \mathrm{~cm}$. Only two cusps were found, the postero-septal and the anterior. They were of normal texture, but short, with the postero-septal valve adherent to the ventricular wall, and the chordæ tendineæ were poorly developed and very fine. In a similar fashion, the papillary muscles were underdeveloped. The valve was certainly incompetent, as the shortened cusps clearly could not meet. The right ventricle was grossly dilated and thin, being almost translucent in places. The trabeculæ in the chamber were very numerous, forming a dense and complicated network. The pulmonary valve ring was normal, as were the cusps.

The endocardium over the anterior surface of the ventricle was thick and white, sections showing very few muscle fibres in this area, with dense subendocardial fibrosis. This was thought to be an old organized mural thrombus, a more recent, flat, laminated mural thrombus being present just beneath the anterior cusp of the atrioventricular valve, the deeper layers of this area being similar to the section showing the subendocardial fibrosis. 


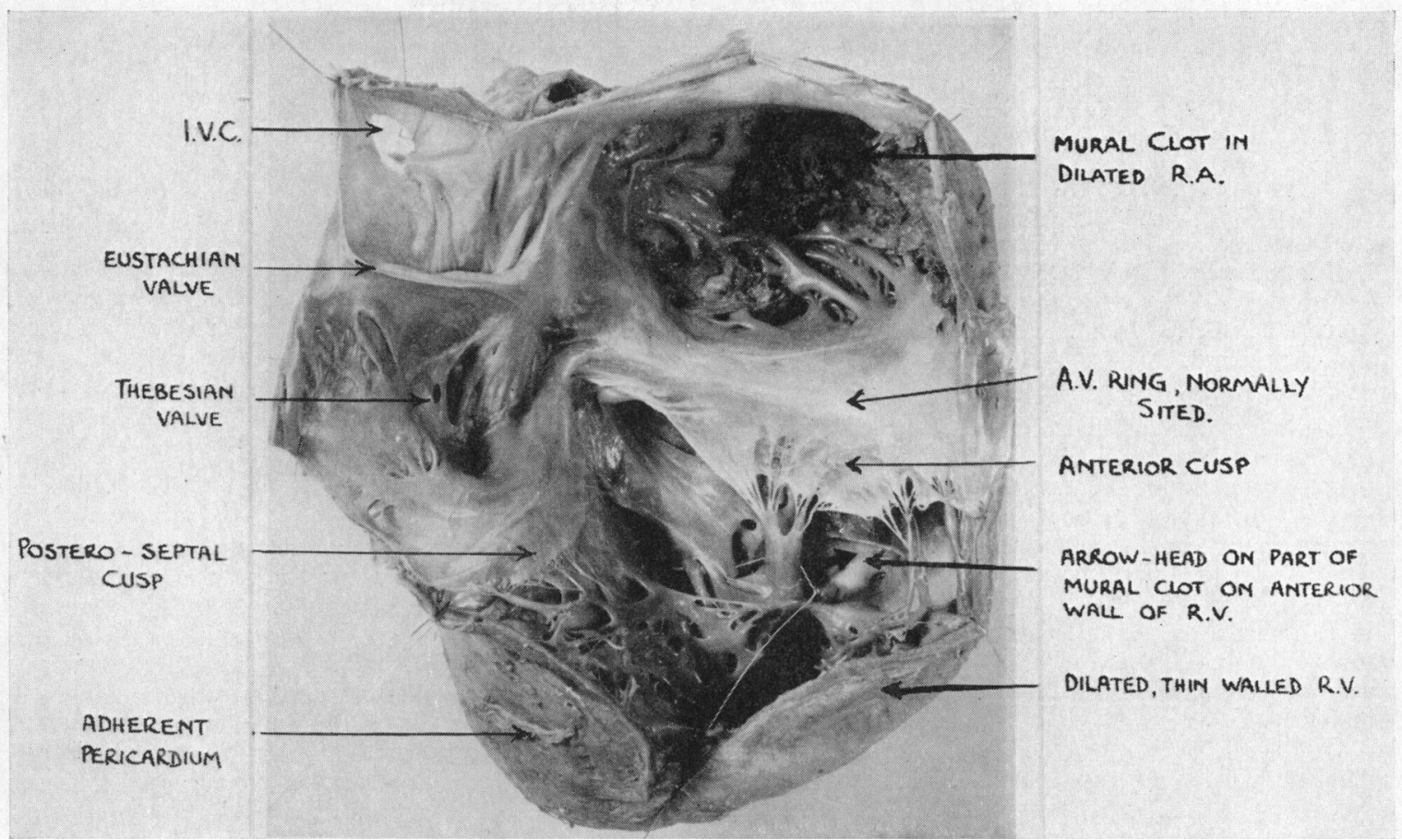

Fig. 2.-Photograph of the opened right atrium and ventricle, showing the greatly enlarged right atrium, the thinwalled ventricle, the bicuspid right atrio-ventricular valve, and the greatly dilated valve ring.

\section{Discussion and Summary}

The necropsy showed that this was a case of congenital bicuspid right atrio-ventricular valve, with gross dilatation of a normally-sited valve ring, different from the Ebstein malformation in that the posterior cusp could not be identified. The right ventricle had not hypertrophied, although presumably the regurgitation through the atrio-ventricular valve had been present from birth. On the contrary, the ventricle had stretched and become thin under the load, but this may have been due to a congenital defect of the muscle itself. The subendocardial fibrosis has not been described in this condition before, although it is an accepted finding in Ebstein's anomaly.

Barritt and Urich (1956) found six previously reported cases and added one of their own, only three of the seven cases being over one year old, and only three having a bicuspid right atrioventricular valve. None of these patients were described as having dilatation of the right ventricle, with thinning of the walls, and none had subendocardial fibrosis.

Moreover, the case described here had no murmurs to suggest the presence of tricuspid incompetence. There was no abnormal jugular pulsation, and the liver was never found to be pulsatile. All these features were probably due to the weakness of right ventricular systole. In fact, the clinical picture appeared typical of Ebstein's anomaly, with the abnormally quiet heart sounds, no visible or palpable right ventricular lift, no murmurs, and oligæmic lung fields. The electrocardiographic findings and the paroxysmal arrhythmias, too, appeared typical.

I would like to thank Dr. E. Noble Chamberlain and Dr. E. Wyn Jones for allowing me to publish this case, Dr. J. Carr Brundret for the performance of the autopsy, and Dr. R. E. B. Hudson for the photograph in Fig. 2, and for his great help in elucidating the autopsy findings.

\section{Reference}

Barritt, D. W., and Urich, H. (1956). Brit. Heart J., 18, 133. 